\title{
A pilot study using an infrared imaging system in prevention of post-endoscopic submucosal dissection ulcer bleeding
}

\author{
Yukinaga Yoshida $\cdot$ Koji Matsuda \\ Naoto Tamai · Kai Yoshizawa $\cdot$ Toshiki Nikami • \\ Haruya Ishiguro $\cdot$ Hisao Tajiri
}

Received: 11 July 2012/ Accepted: 3 January 2013/Published online: 8 February 2013

(C) The International Gastric Cancer Association and The Japanese Gastric Cancer Association 2013

\begin{abstract}
Background Endoscopic submucosal dissection (ESD) for superficial gastric neoplasm is a curative method. The aim of this study was to detect potential nonbleeding visible vessels (NBVVs) by using an infrared imaging (IRI) system.

Methods A total of 24 patients (25 lesions) were consecutively enrolled between March 2010 and December 2010. The day after ESD, endoscopist A (K.M.), who was blinded to the actual procedure of ESD, performed esophagogastroduodenoscopy (EGD) of the post-ESD ulcer base using the IRI system. Endoscopist A marked gray/blue points in the hard-copy images with the IRI system. After the first procedure, endoscopist B (Y.Y.), who was blinded to the results recorded by endoscopist A, performed a second EGD with white light endoscopy and administered water-jet pressure with the maximum level of an Olympus flushing pump onto the post-ESD ulcer base. This test can cause iatrogenic bleeding via application of pressure to NBVV in the post-ESD ulcer.

Results The IRI system detected 58 gray points and 71 blue points. The post-ESD ulcer was divided into the central area and the peripheral area. There were 14 gray
\end{abstract}

Y. Yoshida $(\bowtie) \cdot$ K. Matsuda $\cdot$ N. Tamai

Department of Endoscopy, Katsushika Medical Center,

The Jikei University School of Medicine, 6-41-2 Katsushika-ku,

Tokyo 125-8506, Japan

e-mail: yukinaga29@jikei.ac.jp

K. Yoshizawa $\cdot$ T. Nikami · H. Ishiguro

Division of Gastroenterology and Hepatology,

Katsushika Medical Center, The Jikei University School of

Medicine, Tokyo, Japan

H. Tajiri

Division of Gastroenterology and Hepatology,

The Jikei University School of Medicine, Tokyo, Japan points $(24 \%)$ in the central area and 44 gray points $(76 \%)$ in the peripheral area. There were 19 blue points $(27 \%)$ in the central area and 52 blue points $(73 \%)$ in the peripheral area. There was no significant difference when comparing the distribution of gray points and blue points. Bleeding occurred with a water-jet pressure in 11 of 58 gray points and in none of the blue points $(P=0.000478)$. Among the gray points, bleeding in response to a water-jet pressure occurred in 2 points in the central area and in 9 points in the peripheral area.

Conclusion The IRI system detects visible vessels (VVs) that are in no need of coagulation as blue points, and VVs have a potential risk of bleeding as gray points.

Keywords Gastric neoplasms - Endoscopic submucosal dissection (ESD) $\cdot$ Infrared imaging system (IRI)

\section{Introduction}

Endoscopic submucosal dissection (ESD) is an endoscopic therapeutic method widely accepted for the management of early gastric neoplasms and is less invasive than surgical resection [1-6].However, the procedure still carries a risk of perforation and delayed bleeding, and some patients experience severe bleeding and require a transfusion. In fact, delayed bleeding is estimated to occur in $7 \%$ of patients undergoing ESD [7]. The routine coagulation of nonbleeding visible vessels (NBVVs) in the post-ESD ulcer base can reduce but not eliminate the incidence of delayed bleeding [8]. Thus, it is possible that some visible vessels remain undetected/untreated, which contributes to a persistent risk of hemorrhage.

The infrared imaging system (IRI) can detect the change in wavelength (from 940 to $800 \mathrm{~nm}$ ) that occurs in 
response to hemostatic coagulation. Signals displayed on the color monitor are gray at $920-960 \mathrm{~nm}$ and blue at $790-820 \mathrm{~nm}$. Using an in vivo pig model, Narimiya et al. [9] reported that vessels with blood flow were visualized as "dark gray" as a result of infrared absorption by hemoglobin and that coagulated vessels were visualized as "blue." Based on this study, we previously reported that blue spots on the image represented fully coagulated NBVV, which did not subsequently bleed in response to a water load [10], and that the gray signals represented incompletely coagulated points. Thus, the goal of this study was to assess the ability of an infrared endoscopic imaging system to detect NBVV, which would correspond with a higher risk of bleeding.

\section{Methods}

\section{Patients}

A total of 24 patients (25 lesions) were consecutively enrolled in this study between March 2010 and December 2010 at our hospital. All patients provided written informed consent before participating in this study. Indications for ESD were possible node-negative early gastric neoplasm according to the criteria of Gotoda [7]. Exclusion criteria were as follows: (1) patients with a bleeding tendency (liver cirrhosis, dialysis) or (2) age $>80$ or $<20$ years. The study was approved by the ethics committee of the Jikei University School of Medicine for biomedical research (no. 6081). This study was registered at the University Hospital Medical Network Clinical Trials Registry (UMIN000006545). There are no conflicts of interests between the authors and any company.

\section{ESD procedure}

Indigo carmine was sprayed on the surface of the lesion, following circumferential marking around the lesion. An endosurgical device (Erbotom Intelligent Cut and Coagulation 200; ERBE, Tubingen, Germany) was used. Marking dots were made using a hook-type knife (KD-620LR; Olympus Medical Systems, Tokyo, Japan) with the forced coagulation mode $(25 \mathrm{~W})$. Submucosal injection was fully performed into the submucosal layer of the gastric wall to avoid perforation. A mixture of $0.4 \%$ hyaluronic acid and $10 \%$ glycerin containing a small amount of indigo carmine and epinephrine was used as submucosal fluid injectant. The IT knife 2 (KD-611L; Olympus Medical Systems, Tokyo, Japan) was used as the main electrosurgical knife to dissect the submucosal layer.

After ESD, coagulation of NBVV was performed on the post-ESD ulcer base using hemostatic forceps (FD-416LR;
Olympus Medical Systems) with the soft coagulation mode $(80 \mathrm{~W})$.

\section{Endoscopic protocol}

The day after ESD, endoscopist A (K.M.), who was blinded to the actual procedure of ESD, performed esophagogastroduodenoscopy (EGD) of the post-ESD ulcer base using the IRI system. Endoscopist A marked gray/blue points in the hard-copy images with the IRI system. After the first procedure, endoscopist B (Y.Y.), who was blinded to the results recorded by endoscopist $\mathrm{A}$, performed a second EGD with white light endoscopy (WLE) and administered a water-jet pressure with the maximum level of an Olympus flushing pump (OFP; Olympus Medical Systems) onto the post-ESD ulcer base. The parameters of the flushing pump were $350 \mathrm{ml} / \mathrm{min}$ and $6.3-7.0 \mathrm{kgf} / \mathrm{cm}^{2}$. This test can cause iatrogenic bleeding via application of pressure to NBVV in the post-ESD ulcer. Our hypothesis was that bleeding from vessels in response to the water-jet pressure was a marker of a high risk of delayed bleeding.

If bleeding occurred, endoscopist B performed coagulation with hemostatic forceps.

A second water-jet pressure test was performed after coagulation, and the presence or absence of bleeding was confirmed. In the absence of bleeding, we confirmed that the IRI system shows a change from gray to blue.

After the second EGD, endoscopist B marked the bleeding points in the hard-copy images with WLE. Both results were compared by endoscopist C (N.T.).

\section{Infrared imaging system}

Infrared light is frequently used in medical practice because it is less influenced by scattering and absorption in tissues. These characteristics make infrared light useful to detect subcutaneous venous structures that are not otherwise revealed by visible light [11-13]. The IRI system consists of a light source apparatus (XCLV-260HP; Olympus Medical Systems) and an IR fluorescence endoscope (XGIF-Q260ZIR) with a high-resolution chargecoupled device (CCD) at the end of the scope. Light from the light source first passes through either the infrared-cut filter or the infrared-pass filter to reach the infrared-pass rotary filter. Visible or infrared light emitted by the light source and reflected by an object is then collected by a high-resolution CCD in the endoscope. The signal from the CCD sensor is then processed by the video processor and displayed on a color monitor. In the IRI system, two ranges of infrared rays are emitted by the light source. Red and green channels of the rotary filters pass the light at 790-820 nm, and the blue channel passes light at 920-960 nm (Fig. 1). 
Fig. 1 Schematic diagram of the infrared imaging system

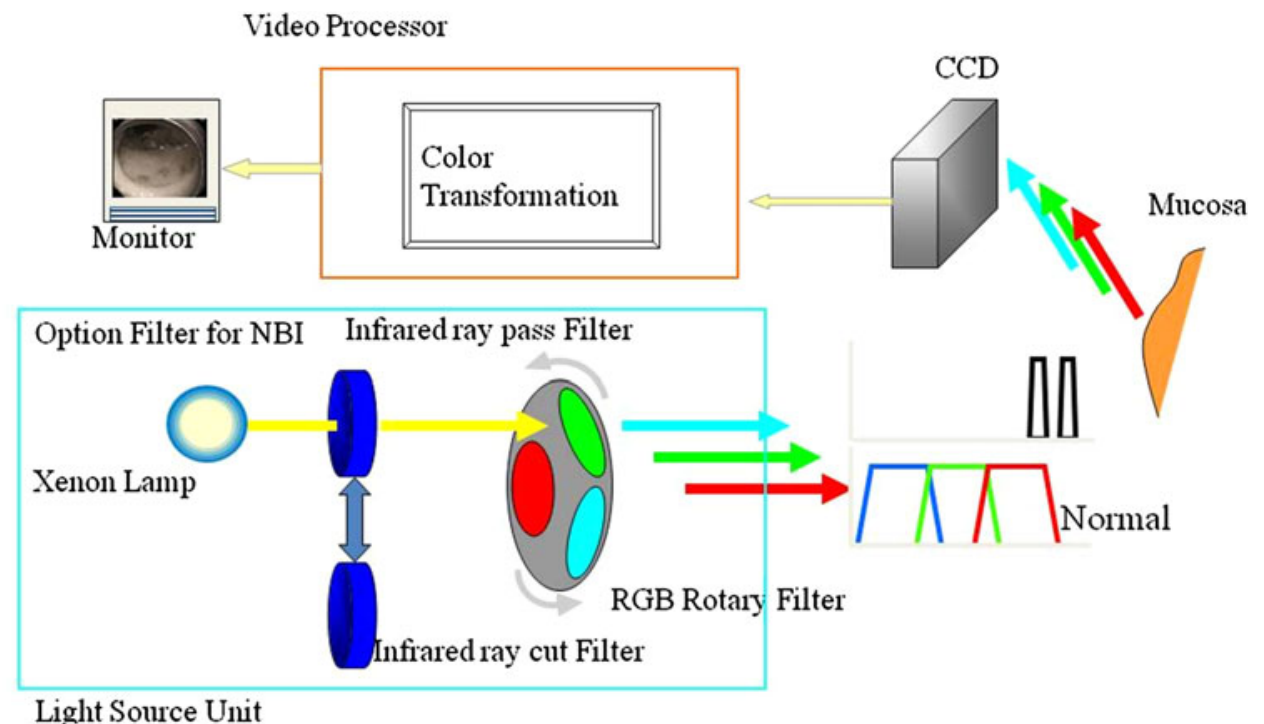

Statistical analysis

The collected data were analyzed using the statistical analysis software STATA 8.0 software (STATA, College Station, TX, USA). Statistical evaluation of the results was performed by the Fisher exact test. A $P$ value was considered statistically significant at the level of 0.05 or less.

\section{Results}

Demographics of the patients and IRI findings are summarized in Table 1. All ESD procedures were performed successfully, and all specimens were obtained by en bloc resection. No complications occurred in this study. Proton pump inhibitors were administered intravenously to all patients on the day before ESD. The day after ESD, this protocol with the IRI system was performed, as already described.

The IRI system detected 58 gray points and 71 blue points. The post-ESD ulcer was divided into the central area and the peripheral area. We defined the central area as the area inside a line that was located at half the distance from the center of the edge of the ulcer. We defined the peripheral area as the area outside of the central area. There were 14 gray points ( $24 \%$ ) in the central area and 44 gray points $(76 \%)$ in the peripheral area. There were 19 blue points $(27 \%)$ in the central area and 52 blue points $(73 \%)$ in the peripheral area.

Bleeding occurred with a water-jet pressure in 11 of 58 gray points and in none of the blue points $(P=0.000478)$ (Table 2; Fig. 2). Among the gray points, bleeding in response to a water-jet pressure test occurred in two points in the central area and in nine points in the peripheral area. All bleeding points were completely coagulated, which resulted in transformation of gray points to blue points. Subsequently, rebleeding did not occur in response to a water-jet pressure test at those coagulated points.

No delayed bleeding occurred within 30 days among the 24 patients.

\section{Discussion}

Post-ESD bleeding occurs in approximately $5 \%$ of patients undergoing ESD and can be life threatening, especially in patients with underlying cardiovascular disease. A previous study reported that factors associated with delayed bleeding included wide resected specimen size ( $>40 \mathrm{~mm}$ ), tumor location, and specific characteristics of the lesions [14-18].

Full coagulation of visible vessels in the post-ESD ulcer may reduce the risk of bleeding. However, NBVVs do not always cause hemorrhage by rupturing the vessel wall. Further, endoscopic coagulation therapy can sometimes result in massive bleeding as a result of enlargement of the ulcer base and perforation. Moreover, it is difficult to precisely assess the risk of bleeding from vessels in the post-ESD ulcer base. Among patients with bleeding peptic ulcers, Cipolletta et al. reported that magnification endoscopy (ME) allowed clear visualization of the vessel wall and could detect high-risk exposed vessels (e.g., protuberant, translucent, or pale) [19]. Uedo et al. reported that use of endoscopic Doppler ultrasound (DOP-US) could help identify areas at risk for bleeding by detecting pulsatile signals [20].

In this study, visible vessels were visualized as blue points (areas of appropriate coagulation) and gray points (areas of insufficient coagulation) on the IRI system, and NBVVs were more prevalent in the peripheral ulcer than in the central ulcer area. Because microvessels are more 
Table 1 Patient characteristics and summary of results

\begin{tabular}{|c|c|c|c|c|c|c|c|c|c|}
\hline \multirow[t]{2}{*}{ Patient } & \multirow[t]{2}{*}{ Location } & \multirow{2}{*}{$\begin{array}{l}\text { Size } \\
(\mathrm{mm})\end{array}$} & \multirow{2}{*}{$\begin{array}{l}\text { Pathological } \\
\text { diagnosis }\end{array}$} & \multirow{2}{*}{$\begin{array}{l}\text { Macroscopic } \\
\text { tumor type }\end{array}$} & \multirow{2}{*}{$\begin{array}{l}\text { Depth of } \\
\text { invasion }\end{array}$} & \multicolumn{2}{|l|}{ Gray points } & \multicolumn{2}{|l|}{ Blue points } \\
\hline & & & & & & Central area & $\begin{array}{l}\text { Peripheral } \\
\text { area }\end{array}$ & Central area & $\begin{array}{l}\text { Peripheral } \\
\text { area }\end{array}$ \\
\hline 1 & $\mathrm{~L}, \mathrm{GC}$ & 20 & SGC & IIa & $\mathrm{sm}$ & & $\bigcirc \bigcirc 00$ & & $\bigcirc \bigcirc \bigcirc$ \\
\hline 2 & M, PW & 8 & SGC & IIc & $\mathrm{m}$ & & & & \\
\hline 3 & L, LC, PW & 25 & SGC & IIc & $\mathrm{m}$ & & $\bigcirc \bigcirc$ & $\bigcirc$ & $\bigcirc \bigcirc 0$ \\
\hline 4 & L, AW & 20 & SGC & IIa & $\mathrm{m}$ & & $\bullet \bullet \bigcirc ০ 0000$ & 00000 & $\bigcirc$ \\
\hline 5 & $\mathrm{~L}, \mathrm{LC}$ & 20 & SGC & IIc & $\mathrm{m}$ & $\bigcirc \bigcirc$ & $\bigcirc \bigcirc$ & & 000000 \\
\hline 6 & $\mathrm{~L}, \mathrm{AW}$ & 10 & Adenoma & IIa & $\mathrm{m}$ & & & & 0000 \\
\hline 7 & $\mathrm{M}, \mathrm{PW}$ & 40 & Adenoma & IIa & $\mathrm{m}$ & $\bigcirc \bigcirc$ & & $\bigcirc \bigcirc 0$ & $\bigcirc \bigcirc$ \\
\hline 8 & $\mathrm{~L}, \mathrm{AW}$ & 5 & SGC & IIc & $\mathrm{m}$ & & $\bigcirc$ & & $\bigcirc \bigcirc$ \\
\hline 9 & $\mathrm{M}, \mathrm{LC}$ & 35 & SGC & IIc & $\mathrm{m}$ & $\bigcirc \bigcirc$ & $\bigcirc \bigcirc$ & $\bigcirc \bigcirc$ & $\bigcirc \bigcirc$ \\
\hline 10 & $\mathrm{~L}, \mathrm{AW}$ & 10 & SGC & IIc & $\mathrm{m}$ & O & $\bigcirc \bullet$ & $\bigcirc$ & $\bigcirc \bigcirc 0$ \\
\hline 11 & $\mathrm{~L}, \mathrm{PW}$ & 6 & SGC & IIa & $\mathrm{m}$ & & $\bigcirc$ & & $\bigcirc$ \\
\hline 12 & $\mathrm{~L}, \mathrm{AW}$ & 5 & SGC & IIc & $\mathrm{m}$ & & $\bigcirc \bigcirc$ & $\bigcirc \bigcirc$ & \\
\hline 13 & L, PW, GC & 7 & SGC & IIc & $\mathrm{m}$ & & $\bigcirc$ & & $\bigcirc \bigcirc$ \\
\hline 14 & $\mathrm{M}, \mathrm{LC}$ & 20 & SGC & IIa & $\mathrm{m}$ & $\bigcirc$ & & $\bigcirc$ & $\bigcirc$ \\
\hline 15 & L, PW, GC & 20 & SGC & IIa & $\mathrm{m}$ & $\bigcirc$ & $\bigcirc \bigcirc$ & & $\bigcirc 00$ \\
\hline \multirow[t]{2}{*}{16} & $\mathrm{~L}, \mathrm{LC}, \mathrm{AW}$ & 14 & SGC & IIa + IIc & $\mathrm{m}$ & $\bigcirc \bigcirc$ & & $\bigcirc$ & \\
\hline & $\mathrm{M}, \mathrm{LC}$ & 8 & SGC & IIc & $\mathrm{m}$ & & $\bigcirc$ & & $\bigcirc$ \\
\hline 17 & $\mathrm{M}, \mathrm{LC}$ & 7 & SGC & IIa & $\mathrm{m}$ & $\bigcirc$ & $\bigcirc$ & & $\bigcirc$ \\
\hline 18 & $\mathrm{M}, \mathrm{AW}, \mathrm{GC}$ & 40 & SGC & IIa & $\mathrm{m}$ & ○ & $\bigcirc \bigcirc$ & & $\bigcirc \bigcirc$ \\
\hline 19 & $\mathrm{U}, \mathrm{LC}$ & 10 & SGC & IIa & $\mathrm{m}$ & & $\bigcirc \bigcirc$ & $\bigcirc$ & $\bigcirc$ \\
\hline 20 & $\mathrm{~L}, \mathrm{AW}, \mathrm{GC}$ & 8 & Adenoma & IIa & $\mathrm{m}$ & & & & 000 \\
\hline 21 & M, PW, LC & 9 & Adenoma & IIa & $\mathrm{m}$ & & $\bigcirc \bigcirc$ & $\bigcirc \bigcirc$ & 0000 \\
\hline 22 & $\mathrm{~L}, \mathrm{LC}$ & 5 & SGC & IIc & $\mathrm{m}$ & & & & $\bigcirc \bigcirc$ \\
\hline 23 & $\mathrm{~L}$ & 5 & SGC & IIc & $\mathrm{m}$ & ○ & & & $\bigcirc 00$ \\
\hline 24 & $\mathrm{~L}, \mathrm{LC}$ & 4 & SGC & IIa & $\mathrm{m}$ & & 000 & & $\bigcirc \bigcirc$ \\
\hline
\end{tabular}

$L$ lower third, $M$ middle third, $U$ upper third, $G C$ greater curvature, $L C$ lesser curvature, $A W$ anterior wall, $P W$ posterior wall, $S G C$ superficial gastric carcinoma, $m$ mucosa, $s m$ submucosa

$\bigcirc$, gray/blue points detected by the infrared imaging (IRI) system;

bleeding point

Table 2 Comparison between gray and blue points on the infrared imaging (IRI) system and bleeding and nonbleeding points on white light endoscopy (WLE)

\begin{tabular}{lllll}
\hline & Bleeding & Nonbleeding & $P$ value & \\
\hline Gray point & 11 & 47 & 58 & ns \\
Blue point & 0 & 71 & 71 & 0.000478 \\
\hline
\end{tabular}

$n s$ not significant

abundant in the vicinity of the mucosal layer than in the submucosal layer, the stumps of vessels may be revealed by circumferential cutting of the mucosal layer.

This study showed that bleeding in response to a waterjet pressure test occurred at some gray points but not at any blue points on IRI, which suggests that NBVVs visualized as gray points are prone to rupture of the vessel wall in response to a water-jet pressure test. In the case of colonic polyps treated with polypectomy, Tamai et al. reported that prophylactic use of endoclips with infrared imaging effectively reduced postpolypectomy bleeding with fewer clips [21]. Routine coagulation of all NBVVs in the postESD ulcer base decreases the incidence of delayed bleeding and is performed as standard practice. The aim of the water-jet test was to apply pressure to the post-ESD ulcer base using a flushing pump. This test has potential to cause iatrogenic bleeding by applying pressure. This study demonstrated that only gray points detected by the IRI system require coagulation with hemostatic forceps after ESD. These data may help reduce the number of points that undergo coagulation and therefore reduce the procedural time.

Bleeding in response to water-jet pressure occurred in only 11 of 58 gray points in this study. Thus, it remains difficult to distinguish bleeding gray points from 

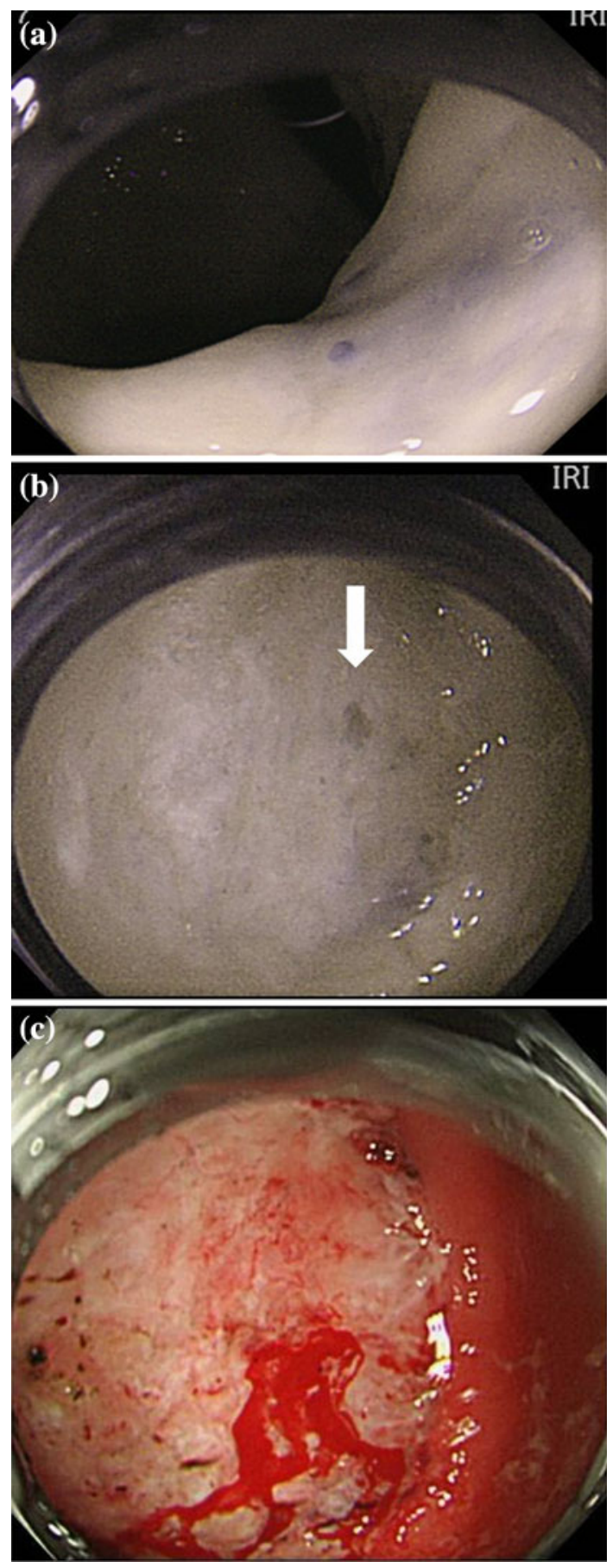

Fig. 2 a The infrared imaging (IRI) system showed blue points, which did not subsequently bleed in response to a water-jet pressure. b The nonbleeding visible vessels (NBVV) were detected as gray points (arrow) by the IRI system in the peripheral area of the postendoscopic submucosal dissection (ESD) ulcer. c After administration of water-jet pressure with a flushing pump, bleeding occurred in the NBVV. Subsequently, the bleeding vessels were treated by hemostatic forceps

nonbleeding gray points as detected by the IRI system. IR imaging shows only slight color (e.g., gray and blue) without clear visualization of the vessel form or diameter.
However, it is important to fully investigate the peripheral area of the post-ESD ulcer during the second-look endoscopy, because 9 of 11 gray bleeding points were located within the peripheral area.

The most common $(70 \%)$ diameters of NBVV ranged from 1 to $2 \mathrm{~mm}$ in patients with bleeding peptic ulcer. The incidence of further bleeding directly correlates with the size of the NBVV, with a smaller NBVV associated with a lower incidence of bleeding ( $1 \mathrm{~mm}, 34 \% ; 2 \mathrm{~mm}, 44 \%$; $3 \mathrm{~mm}, 52 \%$; $4 \mathrm{~mm}, 60 \%$; $5 \mathrm{~mm}, 67 \%$; >6 mm, $100 \%$ ) [22]. Furthermore, peripheral location of an NBVV within the ulcer is associated with a higher incidence of bleeding when compared with a central ulcer location $(56 \%$ vs. $20 \%$ ) [23]. However, these results from peptic ulcer cases may differ from results in a post-ESD ulcer.

This study was limited by the small patient population and by investigation within a single center. Moreover, this study did not make comparisons between groups with or without coagulation visualized as gray points.

\section{Conclusion}

Bleeding in response to water-jet pressure occurred in only gray points in the peripheral area. The IRI system allows the visualization of the "high risk of bleeding" more precisely than WLE. Thus, limiting coagulation to these points, with special attention to the peripheral area of the ulcer, may reduce unnecessary coagulation and reduce procedural time while still minimizing the risk of delayed bleeding.

Acknowledgment We thank Kazuki Sumiyama M.D (The Jikei University School of Medicine, Tokyo, Japan) for invaluable help with this study.

Conflict of interest The authors declare that there are no conflicts of interest associated with the present study.

\section{References}

1. Gotoda T, Yamamoto H, Soetikno RM. Endoscopic submucosal dissection of early gastric cancer. J Gastroenterol. 2006;41: 929-42.

2. Chung IK, Lee JH, Lee SH, Kim SJ, Cho JY, Cho WY, et al. Therapeutic outcomes in 1000 cases of endoscopic submucosal dissection for early gastric neoplasms: Korean ESD Study Group multicenter study. Gastrointest Endosc. 2009;69:1228-35.

3. Dinis-Ribeiro M, Pimentel-Nunes P, Afonso M, Costa N, Lopes C, Moreira-Dias L. A European case series of endoscopic submucosal dissection for gastric superficial lesions. Gastrointest Endosc. 2009;69:350-5.

4. Neuhaus H. Endoscopic submucosal dissection in the upper gastrointestinal tract: present and future view of Europe. Dig Endosc. 2009;21(suppl 1):S4-6.

5. Othman MO, Wallace MB. Endoscopic mucosal resection (EMR) and endoscopic submucosal dissection (ESD) in 2011, a Western perspective. Clin Res Hepatol Gastroenterol. 2011;35:286-94. 
6. Probst A, Pommer B, Golger D, Anthuber M, Arnholdt H, Messmann H. Endoscopic submucosal dissection in gastric neoplasia: experience from a European center. Endoscopy. 2010;42: 1037-44.

7. Gotoda T. Endoscopic resection of early gastric cancer. Gastric Cancer. 2007;10:1-11.

8. Takizawa K, Oda I, Gotoda T, Yokoi C, Matsuda T, Saito Y, et al. Routine coagulation of visible vessels may prevent delayed bleeding after endoscopic submucosal dissection: an analysis of risk factors. Endoscopy. 2008;40:179-83.

9. Narimiya N, Isshi K, Nakamura Y, Tajiri H. Observation on infrared image of mucosal defects caused by endoscopic mucosal resection using electronic endoscopy. Gastroenterol Endosc. 2005;47:2361-70.

10. Nakayoshi T, Tamai N, Matsuda K, Tajiri H. The infrared ray imaging (IRI) system may predict delayed-type bleeding from the mucosal defect after EMR or ESD for the gastric tumors. Gastrointest Endosc. 2007;65(5):AB351.

11. Gostout CJ, Jacques SL. Infrared video imaging of subsurface vessels: a feasibility study for the endoscopic management of gastrointestinal bleeding. Gastrointest Endosc. 1995;41:218-24.

12. Hayashi N, Kawano S, Tsuji S, Tsujii M, Takai Y, Nagano K, et al. Identification and diameter assessment of gastric submucosal vessels using infrared electronic endoscopy. Endoscopy. 1994;26:686-9.

13. Mataki N, Nagao S, Kawaguchi A, Matsuzaki K, Miyazaki J, Kitagawa $\mathrm{Y}$, et al. Clinical usefulness of a new infrared videoendoscope system for diagnosis of early stage gastric cancer. Gastrointest Endosc. 2003;57:336-42.

14. Huang Y, Kakushima N, Takizawa K, Tanaka M, Ikehara H, Yamaguchi Y, et al. Risk factors for recurrence of artificial gastric ulcers after endoscopic submucosal dissection. Endoscopy. 2011;43:236-9.

15. Jang JS, Choi SR, Graham DY, Kwon HC, Kim MC, Jeong JS, et al. Risk factors for immediate and delayed bleeding associated with endoscopic submucosal dissection of gastric neoplastic lesions. Scand J Gastroenterol. 2009;25:1-7.

16. Mannen K, Tsunada S, Hara M, Yamaguchi K, Sakata Y, Fujise $\mathrm{T}$, et al. Risk factors for complications of endoscopic submucosal dissection in gastric tumors: analysis of 478 lesions. J Gastroenterol. 2010;45:30-6.

17. Matsushita M, Mori S, Tahashi Y, Uchida K, Nishio A, Okazaki $\mathrm{K}$. The site of delayed bleeding suggests the cause of bleeding after endoscopic submucosal dissection. Scand J Gastroenterol. 2010;45:1127-8.

18. Matsushita M, Mori S, Tahashi Y, Uchida K, Nishio A, Okazaki $\mathrm{K}$. Immediate bleeding during endoscopic submucosal dissection: a predictor of delayed bleeding? Gastrointest Endosc. 2011;73:413-4.

19. Cipolletta L, Bianco MA, Salerno R, Prisco A, Marmo R, Cipolletta $\mathrm{F}$, et al. Improved characterization of visible vessels in bleeding ulcers by using magnification endoscopy: results of a pilot study. Gastrointest Endosc. 2010;72:413-8.

20. Uedo N, Takeuchi Y, Ishihara R, Hanaoka N, Inoue T, Kizu T, et al. Endoscopic Doppler US for the prevention of ulcer bleeding after endoscopic submucosal dissection for early gastric cancer: a preliminary study (with video). Gastrointest Endosc. 2010;72: 444-8.

21. Tamai N, Matsuda K, Sumiyama K, Isshi K, Narimiya N, Tajiri $\mathrm{H}$, et al. Prophylactic hemostasis for postpolypectomy mucosal defect using endoclip under infrared imaging endoscopy. Surg Technol Int. 2010;19:91-6.

22. Lin HJ, Perng CL, Lee FY, Lee CH, Lee SD. Clinical courses and predictors for rebleeding in patients with peptic ulcers and nonbleeding visible vessels: a prospective study. Gut. 1994;35: 1389-93.

23. Amano Y, Moriyama N, Suetsugu H, Ishimura N, Imaoka T, Komazawa Y. Which types of non-bleeding visible vessels in gastric peptic ulcers should be treated by endoscopic hemostasis? J Gastroenterol Hepatol. 2004;19:13-7. 